Review Article:

\title{
Spinal Manifestations of Neurofibromatosis: An Update
}

\author{
Kaveh Haddadi ${ }^{*}$ (D), Saeed Kargar Soleiman Abad ${ }^{2}$ (D), Seyed Mohammad Hashemi Amir ${ }^{2}$, Mehdi Pooladi $^{2}$ (D)
}

1. Orthopedic Research Center, Faculty of Medicine, Mazandaran University of Medical Sciences, Sari, Iran

2. Student Research Committee, Faculty of Medicine, Mazandaran University of Medical Sciences, Sari, Iran

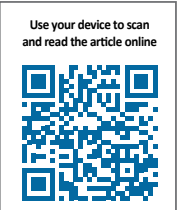

Citation: Haddadi K, Kargar Soleiman Abad S, Hashemi Amir SM, Pooladi M. Spinal Manifestations of Neurofibromatosis: An Update. Iran J Neurosurg. 2020; 6(4):169-180. http://dx.doi.org/10.32598/irjns.6.4.1

d oi : $\mathrm{http://dx.doi.org/10.32598/irjns.6.4.1}$

\section{(c) (1) (\$)}

Article info:

Received: 04 Apr 2020

Accepted: 20 Aug 2020

Available Online: 01 Oct 2020

Keywords:

Spine, Manifestations, Neurofibromatosis

\section{A B STRACT}

Background and Aim: Neurofibromatosis-1 (NF1) is a common genetic condition in children. It is becoming increasingly recognized that in neurofibromatosis, there might be anomalous development of bone with or without any local anomaly of neuroectodermal basis. This review was conducted to highlight the different features of spinal disorders in this congenital disease.

Methods and Materials/Patients: Different search engines were used in this research. After going through the results and discarding the repeated ones, 2 reviewers began to inspect the studies independent of one another. In case of any disagreements between the reviewers over the inclusion of certain research material into the study, the final decision was made by the senior author. In the end, accepted research materials were used as needed in categorizing different types of spinal injuries.

Results: Skeletal defects are among the most effective complications on the quality of life of patients. Bone deformities, osteoporosis, osteopenia, reduction of bone mass density, and spinal osteopathy such as scoliosis among such defects. Although the relative prevalence of spinal defects in neurofibromatosis type 1 is not clear, scoliosis can be considered the most common type of spinal deformity in this illness to the point it is present in 10 to $71 \%$ of cases. Thus, spine surgeons may face numerous common challenging conditions in NF1 patients like scoliosis, spondylolisthesis, and dural ectasia.

Conclusion: As NF1 distresses several organ systems, radiologic spine screening is important in patients with NF1 and patients are likely to profit most from a multidisciplinary treatment policy.

\section{* Corresponding Author: \\ Kaveh Haddadi, MD.}

Address: Orthopedic Research Center, Faculty of Medicine, Mazandaran University of Medical Sciences, Sari, Iran

Tel: +98 (911) 1598040

E-mail: kavehhaddadi56@gmail.com 


\section{Highlights}

- Neurofibromatosis-1 (NF1) is a common genetic condition in children in which there might be anomalous development of bone with or without any local anomaly of neuroectodermal basis.

- Skeletal defects are among the most effective complications on the quality of life of patients.

- Scoliosis can be considered the most common type of spinal deformity in this illness to the point that it is present in $10 \%$ to $71 \%$ of cases.

- Radiologic spine screening is important in patients with NF1 and patients are likely to profit most from a multidisciplinary treatment policy.

\section{Plain Language Summary}

It is becoming increasingly recognized that in neurofibromatosis there might be anomalous development of bone with or without any local anomaly of neuroectodermal basis. Skeletal defects are among the most effective complications on the quality of life of patients. Bone deformities, osteoporosis, osteopenia, reduction of bone mass density, and spinal osteopathy such as scoliosis are among such defects. Spine surgeons may encounter common challenging conditions in NF1 patients like scoliosis, spondylolisthesis, and dural ectasia. This review was conducted to highlight the different features of spinal disorders in this congenital disease.

\section{Introduction}

eurofibromatosis is an autosomal dominant disease which can be categorized into 3 subtypes: 1-NF1 2-NF2 3-schwannoma. This disease is a type of familial predisposition syndrome that can cause the spread of benign and malignant tumors all over the patient's body. Neurofibromatosis can be sorted into the 2 categories of peripheral or type-1 neurofibromatosis and central or type-2 neurofibromatosis [1-4].

NF1, which was initially described by von Recklinghausen as a neurocutaneous syndrome is in fact a hereditary disease resulting from a mutation in the NF1 gene which exists on chromosome 17 (17q11.2). This disease is the most commonly occurring single-gene disorder of human beings, with a prevalence rate of 1 in 3000 to 4000. Type-1 neurofibromatosis does not pertain to a certain race or gender; however, a hereditary background can influence the occurrence of this disease to a point that $50 \%$ of the cases reported family members afflicted with this disease in their family history and the other $50 \%$ were the result of new mutations [5-9].

Normally, this gene is responsible for the creation of neurofibromin-a GTPase activator protein with tumorsuppressing functions. Under normal circumstances, this protein inhibits the activity of KRAS, a cancer proto-oncogene and also affects the levels of intracellular CAMP (Cyclic adenosine monophosphate); so much so that a decrease in the expression of the NF1 gene reduces the levels of cAMP inside cells [10-12].Moreover, an increase in the activity of osteoclast the cells has been reported in mice with NF1 haploinsufficiency (NF1+/-) [13-16].

Generally speaking, neurofibromatosis manifests through the unnatural proliferation of neural crest cells. Neurofibromatosis type 1 affects almost every single organ of the body. It is accompanied by cutaneous symptoms such as café-au-lait spots, Lisch nodules, oral lesions, as well as Central Nervous System tumor (CNS tumor) tumors such as nerve sheath tumors, neural pathway glioma, glioblastoma, stromal tumors, neuroendocrine carcinoma, rhabdomyosarcoma, pheochromocytoma, leukemia, and breast cancer. In addition to neoplastic and cutaneous symptoms, this disease can also manifest itself through neuropsychiatric symptoms such as learning disabilities, functional disabilities, lack of attention, and a decrease in social competence which can lead to a decrease in social participation and eventually, social isolation. One can point to neurocognitive dysfunctions, cardiovascular dysfunctions, epilepsy, musculoskeletal debilitations, reduction of muscle size, and general weakening of muscles as some of the other impairments resulting from neurofibromatosis $[4,5,17]$. 
Skeletal defects are among the most impactful complications on the quality of life of patients. Bone deformities, osteoporosis, osteopenia, reduction of bone mass density, and spinal osteopathy such as scoliosis among such defects [18]. Although the relative prevalence of spinal defects in neurofibromatosis type 1 is not clear, scoliosis can be considered the most common type of spinal deformity in this illness to the point it is present in $10 \%$ to $71 \%$ of cases. Meanwhile, the rate of prevalence of NF1 in patients afflicted with scoliosis is $3 \%$. Despite the fact that spinal defects are among the least lethal complications of NF1, they have a considerable impact on the quality of life of patients and morbidity of this disease [19]. Given the limited specific and categorized articles about bone and spine involvement in neurofibromatosis, this review was conducted to highlight the different features of spinal disorders in this congenital disease.

\section{Methods and Materials/Patients}

The goal of this study is to review the spinal complications of neurofibromatosis. Five search engines were used in this research: PubMed, Scopus, ResearchGate, Science Direct, and Google Scholar. In searching for neurofibromatosis, the 3 forms of neurofibromatosis, neurofibromatosis 1 , and neurofibromatosis I were used. And as for spinal defects, the words spine, spinal, scoliosis, kyphosis, vertebral, and vertebral column were searched for. When executing the search itself, "and" was used between words, and the search was limited by title/abstract. After going through the results and discarding the repeated ones, 2 reviewers began to inspect the studies independent of one another. In case of any disagreements between the reviewers over the inclusion of certain research material into the study, the final decision was made by the senior author. In the end, accepted research materials were used as needed in categorizing different types of spinal injuries.

\section{Results}

Neurofibromin 1 pathway effector gene

The NF1 gene is responsible for a number of tasks performed through a multitude of pathways, including a positive regulatory effect on the production of CAMP and a negative regulatory effect on the expression of the RAS gene [20].

Neurofibromin induces the synthesis of cAMP from adenosine triphosphate (ATP). ERGO, a reduction in the expression of NF1 results in the lowering of intracellular cAMP levels which is observed in some cells such as astrocytes and neurons. Reduced cAMP levels also reduce protein kinase activity [21]. Also, neurofibromin specifically belongs to the RAS GTPase activator family [22]. Considering the proto-oncogenous role of RAS and the related tumor-suppressing activity of NF1, the value of the latter becomes evident [23].

\section{Clinical manifestation of NF1}

The clinical manifestation and signs and symptoms of NF1 disease covers a vast spectrum, many of which may not emerge at the time of the patient's birth and would appear at a later stage, during childhood or adolescence, making proper diagnosis difficult [24]. Café-au-lait spots appear in more than $90 \%$ of patients and can be considered the most frequently occurring symptom of this disease $[25,26]$. The existence of these spots in the inguinal and the axillary region has the most specificity for NF1 if seen in children [26]. Some of the other forms of manifestations that might take place in patients can be related to optic pathway tumors, for glioma is one of the diseases that may result from this syndrome [18], appearing mostly in young children. Lisch nodules of the iris is one of the other symptoms of this syndrome and musculoskeletal and orthopedic defects and pseudarthrosis are some of the others [4, 21, 24].

The criteria for neurofibromatosis diagnosis was set in the National Institutes of Health Consensus Development Conference held in 1987. Neurofibromatosis can be diagnosed by the simultaneous presence of 2 or more of the items mentioned below (Table 1).

Finally, neurofibromatosis can be divided into bone tissue involvement and soft tissue involvement, and each of them can be divided into primary and secondary involvement as shown below [4]:

I. Bone involvement linked to.

I-A. Primary bone changes secondary to mesodermal dysplasia.

I-B. Secondary bone changes that are caused by the effects of compression (usually tumors).

I-C. Mixed bone changes that are caused by a combination of mesodermal dysplasia and the effects of compression.

II. Soft tissue involvement.

II-A. Primary soft tissue involvement (tumoral). 
Table 1. Diagnostic criteria for NF1 [27]

\begin{tabular}{cl}
\hline No. & \multicolumn{1}{c}{ Diagnostic Criteria } \\
\hline 1 & Six or more café-au-lait spots (15 mm or larger after puberty and $5 \mathrm{~mm}$ or more in prepubertal individuals) \\
2 & Two or more neurofibromas of any type or 1 or more plexiform neurofibroma \\
3 & $\quad$ Freckling in the axilla or groin \\
4 & $\begin{array}{l}\text { Optic glioma (tumor of the optic pathway) } \\
6\end{array} \quad \begin{array}{l}\text { A distinctive bony lesion such as sphenoid wing dysplasia or thinning of the cortex of the long bones (with or without pseu- } \\
\text { doarthrosis) }\end{array}$ \\
\hline 7 & A first-degree relative with NF1
\end{tabular}

Adapted with permission from Arch Neural 1988; 45:575-578.

\section{Nerve sheath tumors:}

a. Benign: Neurofibromas, Focal singular, Focal multiple, Plexiform, Schwannomas (rare),

b. Malignant: neurofibrosarcoma/malignant peripheral nerve sheath tumors.

\section{Other tumors:}

a. Medulloblastoma,

b. Astrocytoma,

c. Meningioma,

d. Ganglioneuroma.

II-B. Secondary soft tissue involvement

\section{Dural cystic dilation}

\section{Lateral meningocele}

Bone involvement

It was recently discovered that neurofibromin has an important role in the development of the skeletal system, [26-28] so much so that a flaw in this gene can result in severe defects in limb morphology and development and people afflicted with NF1 have lower bone mineralization levels compared to healthy individuals [29]. Primary bone involvement-also known as primary bone tissue dysplasia-is in fact compromised bone tissue vulnerable to erosion or hypoplasia that can affect any part of the vertebral column and progress to other parts as well [30-32]. This involvement is responsible for the dystrophic appearance of the spine. Additionally, studies have introduced other forms of bone tissue involvement due to neurofibromatosis such as growth defects, atrophy, hypertrophy, congenital bone defects, hyperplasia or hypoplasia or a combination of the two originating from the bone tissue itself, osteomalacia, intra-osseous cystic lesions and pseudoarthrosis [32]. A number of other spinal injuries can also be attributed to this type of skeletal change such as scoliosis, vertebral scalloping, and meningocele which is a protrusion of the dural sac due to an enlarged point between the vertebrae [33].

Spondylolisthesis is one of several disorders that experiences a clear rise in occurrence in patients afflicted with NF1 [29]. This disorder is often accompanied by dural ectasia [26].

Secondary bone involvement appears in two forms. In some cases, this change is caused by pressure from sources other than the bone itself which most commonly is a peripheral nerve sheath applying pressure to the bone, changing its form and creating bone tissue involvement. In other cases, this pressure comes from tumors that originate from the tumor itself [4].

\section{Congenital pseudarthrosis of the tibia and other bony dysplasias}

Congenital tibial dysplasia or Congenital Pseudarthrosis of the Tibia (CPT), is a comparatively rare condition (1 in 250,000 births) [34]. But, it is found more frequently in NF1 patients. While only $5 \%$ of patients with NF1 are finally diagnosed with $\mathrm{CPT}, 75 \%$ of all patients with CPT have NF1 [34]. 


\section{Metabolic bone disorders}

Loss of neurofibromin function is a reason for generalized metabolic bone disorders in NF1. Multiple sources have confirmed a general reduction in bone mass in the NF1, including children. The levels of bone mineral density in the lumbar spine were found to be lower than other bones [35].

\section{Growth patterns}

Overgrowth of tissues in one section of the child body is one of the documented characters of NF1, as unilateral segmental hypertrophy, or gigantism. Sub-periosteal bone growing has similarly been distinguished in combination with NF1 and consequences in irregular elongation of bone [36]. Another tendency is short stature, disturbing up to $40 \%$ of patients [37].

\section{Spinal neurofibromatosis}

One-tenth to one-third of pediatric cases of neurofibromatosis manifest some form of spinal deformities [38].

\section{Pathologic findings}

Spinal deformities are very common in NF1 patients. This type of deformity can be bilateral or unilateral; however, the bilateral form is much more uncommon [39]. Scoliosis is the most commonly occurring musculoskeletal physical manifestation of NF1, as well as the most commonly occurring coronal plate deformity [40]. Erosion, primary mesodermal dysplasia, and osteomalacia are the most important suggested reasons for bone deformities. Different studies have reported varying prevalence rates for scoliosis in patients afflicted with NF1-from $2 \%$ to $71 \%$ [4, 41-44].

Meanwhile, the prevalence rate of NF1 in individuals with symptomatic scoliosis is $2 \%$ to $3 \%[19,20]$. By using plain radiography and the presence/absence of skeletal dysplasia, coronal plate deformities can be put into 2 categories: 1-non-dystrophic, 2-dystrophic [33]. Determining whether or not the deformity is dystrophic or non-dystrophic is valued for its impact on prognosis and the therapeutic process [41]. Cobb's method can be used to determine the severity of scoliosis [45].

Non-dystrophic: is less severe, more common, and less rapidly progressing than dystrophic scoliosis [33]. Its signs and symptoms and treatment methods are similar to normal idiopathic scoliosis [46]. Non-dystrophic scoliosis can at times change into its dystrophic form due to modulation [14]. Studies have observed that the most important factor in the manifestation of modulation is the age at which scoliosis first presents itself, so much so that modulation was present in $81 \%$ of patients who were afflicted with scoliosis before the age of 7. Also, Durani et al. stated the ratio of modulation in patients at $65 \%$ [38]. The most common physical manifestation of this type of scoliosis is a longer curve [21, 27].

Dystrophic: usually presents itself with kyphoscoliosis in the thoracic region of the vertebrae [43]. However, this is not the first sign of this disorder to make itself seen and dystrophic curves are usually visible in radiographies after the age of 3 [32]. This type of deformity is characterized by sharply angulated short segments and single curvatures in the thoracic region that involve 4 to 6 vertebrae and presents itself with at least 3 dystrophic features [47].

On the other hand, the presence and progress of dystrophic complications in patients may result in lateral, anterior, or posterior (the most common form) vertebral scalloping of the vertebral bodies [33]. This is always caused by erosion which in turn may be caused by neurogenic tumors like meningocele [48]. Some of the other changes seen in the dystrophic type are severe rotation of the apical vertebra, defective pedicles, widening of the spinal canal or the intervertebral foramina, sharpening of the vertebral margins, portion of the second rib, spindling appearance of the transverse process, or a paravertebral mass $[29,38,43,46]$.

Penciling of the ribs is another change in the dystrophic type which is defined as a rib whose width is narrower than the narrowest part of the second rib and is the most prevalent type of dystrophic osseous change. In addition to being a cause of the deformity, penciling of the ribs can lead to an increase in the likelihood of their dislocation and there have been reports of penciled ribs entering the spinal canal and causing paralysis [25, 26].

These changes are supposed to be as a result of the presence of intraspinal neurofibromas, primary dysplasia, pseudomeningoceles, and dural ectasia that erode the surrounding bony structures and cause primary bone dysplasia [38, 49] which is recognizable in the normal graphs of the spinal column. In many cases, dystrophic scoliosis is accompanied by kyphosis which manifests as kyphoscoliosis, its manifestation is obviously linked with the progress of the deformity $[43,50]$. Dystrophic deformities can normally be observed in the thoracic and lumbar areas $[49,50]$. However, cases have been reported involving this type of deformity manifesting itself 
Table 2. Typical dysplastic changes evident on plain radiographs in patients with NF1

\section{Typical Dysplastic Changes}

Vertebral scalloping (that can only be considered present when the depth of the scalloping is more than 4 millimeters in the lumbar spine or more than 3 in the thoracic spine) -this is linked to either dural ectasia or neural tumors

Rib penciling (defined as when the width of a rib is narrower than the narrowest part of the second rib)

Transverse process spindling

Vertebral wedging

Paravertebral soft tissue mass

Short curve with severe apical rotation

Intervertebral foraminal enlargement

Widened interpediculate distances

Dysplastic pedicles

as kyphoscoliosis in the cervical region [48, 49]. There have also been reports claiming rotatory dislocations as an accompanying complication that might be observed alongside scoliosis and kyphosis in patients [43, 49, 50]. Typical dysplastic changes evident on plain radiographs in patients with NF1 are presented in Table 2.

\section{Soft tissue involvement}

\section{Spinal tumors}

Tumors are the primary cause of soft tissue involvement. Most spinal tumors belong to the intraforaminal type and a lesser percentage of them are of the intramedullary and the extramedullary types [26]. Spinal tumors can generally be categorized into 2 groups:

The first are tumors that are not from the peripheral nerve sheath and may have a different origin than the spine. These tumors may originate from glial cells or the neuroectoderm such as astrocytoma, oligodendroglio$\mathrm{ma}$, and pineoblastoma [51, 52]

The second group are tumors that originate from the peripheral nerve sheath [53]. These tumors can again be divided into 2 groups: neurofibroma and shwannoma. All of these tumors can appear in benign and malignant forms.

The probability of occurrence of neural tumors in NF1 patients is very high to the point that in a multicenter study carried out in multiple countries on 280 cases, the manifestation rate of plexiform neurofibroma was declared to be at $25 \%$, optic glioma at $13 \%$, brainstem glioma $2.5 \%$, and astrocytoma at $2 \%$ of patients [38].

Neurofibroma: neurofibromas are the most common type of peripheral nerve sheath tumor. It is a benign tumor comprised of epineurium and connective tissue. Neurofibromas are comprised of a combination of Schwann cells, fibroblasts, mast cells, and perineural cells in a variably myxoid background [54]. The main cause for this tumor is a mutation in the NF1 gene. This tumor's histopathology is either in the form of ovoid or fusiform. In most cases, neurofibromas are caused by sporadic mutations but in $10 \%$ of cases, this tumor appears in individuals afflicted with neurofibromatosis. This tumor can appear in any part of the body and is not specific to a particular region [55]. Neurofibromas are categorized into 3 groups: localized which is the most common form in adults between the ages of 20 to 40 , diffuse, and plexiform. The diffuse and plexiform types are more common in children, in a manner that plexiform neurofibromas are rare in children above the age of 5 [56]. The detection of plexiform neurofibromas is generally treated as a pathognomonic criterion for neurofibromatosis in children. Fifty percent of this type appears in the torso, $30 \%$ and $20 \%$ in the head and neck but more uncommonly appear in other areas such as the occipital region, mandible, and even the lungs [26, 57]. Race and gender have no effects on the probability of affliction. In most cases, these tumors are benign and have a good prognosis but certain cases of this tumor can become malignant. Currently, the best treatment for this tumor is complete resection where removal of 
the tumor is possible [58]. The probability of recurrence is low in this tumor. In certain cases, in the plexiform type, surgery is not an option in which case the growth of the tumor must be monitored. These tumors can appear in the spine in intramedullary, extramedullary, or paravertebral form and due to their location, they can affect the other parts of the spine. For example, they can apply pressure on the bones or create a hypoplastic state in them $[59,60]$. Also, neurofibromas can change from benign to malignant, in which case they might invade the surrounding bone or soft tissue. It has been estimated that $50 \%$ to $80 \%$ of peripheral nerve sheath tumors occur sporadically and $20 \%$ to $50 \%$ are related to neurofibromatosis. The prevalence of this tumor in a normal population is roughly $0.001 \%$ while in individuals afflicted with neurofibromatosis, it increases to $2 \%$ to $5 \%$. On the other hand, the peak of appearance in a normal population is in the $7^{\text {th }}$ decade of life while in patients with NF1, it mostly occurs in the $3^{\text {rd }}$ and $4^{\text {th }}$ decades. Plexiform nerofibromas are the type most likely to progress towards malignancy $[61,62]$.

Schwannoma: schwannomas are another type of peripheral nerve sheath tumor that are prominently comprised of Schwann cells. This type of tumor can also occur due to mutations in the NF1 gene at the germinal or somatic cell level. Studies have unveiled that the expression of this gene in Schwann cells is marginally higher than in other cells and a lack of mutation of one or both alleles of the NF1 gene can lead to a decreased expression of these genes causing an increase in cell division rate the creation of neoplasms in these cells which in turn forms schwannomas [52, 63]. From a histological perspective, these tumors are usually confined to a limited area and are more cellular, and Verocay bodies and Antoni A and Antoni B areas can be seen in them [64].

Dural ectasia: The most prominent soft tissue involvement in the brain and spine, dural ectasia is the local and progressive widening of the dural sac $[33,34]$. Dural ectasia can be due to enlarged neural foramina, elongated cervical pedicles, or an increase in the hydrostatic pressure of the cerebrospinal fluid affecting a weaker part of the dura, all of which lead to the creation of extra space for the spine $[33,34]$. This is a rare complication in a normal population but is common in people with connective tissue disorders such as NF1 [65]. In cases of NF1, dural ectasia most commonly occurs in the thoracic region of the spine but it might occur in other regions such as the lumbosacral as well [66]. Dural ectasia can be accompanied by posterior vertebral scalloping formation and meningocele formation, which often leads to vertebral subluxation and dislocation requiring surgical intervention [67].

Abnormalities of the cervical spine: Abnormalities of the cervical spine are common in patients with NF1. In a famous series of NF1 patients, cervical spine involvement was found in $30 \%$, including dysplastic changes, cervical kyphosis, and rotatory subluxation [68].

The deformity may cause a cervical spondylolisthesis and severe spondyloptosis [69]. The important symptoms are neck pain or neurologic symptoms. Thus, radiologic screening is important in patients with NF1 and scoliosis [70].

Other spinal abnormalities: Lumbar spondylolisthesis can originate from NF1, but regularly, if spondylolisthesis developes, it is combinined with foraminal neurofibroma or dural ectasia. Spondylolisthesis in combination with dural ectasia is a big challenge for the spine surgeon since the narrowed pedicles can prevent pedicle screw fixation.

There are some reports of effective reduction with lumbar pedicular and interbody fusion in a patient with NF1 combined with severe spondylolisthesis and dural ectasia [70, 71].

Rare spinal complication: Apart from those mentioned above, other forms of spinal involvement do happen in NF1 patients but they are less common such as vascular injuries including vertebral artery aneurysms [72-79].

Another type of injury which is considered rare but does have dire consequences is demyelinating polyneuropathy. It has a high mortality rate and although it is one of the least likely forms of manifestation for NF1, timely diagnosis and treatment can have a considerable impact on our management of the complications and the patient's quality of life $[80,81]$.

Finally, although in contrast to various physical illnesses in children, such as trauma, spine diseases, behavioral disorder, and hydrocephalous [82-85], the prevalence of NF disease is infrequent, yet there is a lot of doubt about the best treatment option for this condition in pediatric patients.

\section{Conclusion}

NF1 is a common genetic disorder. It is becoming progressively documented that in neurofibromatosis there might be anomalous development of bone with or 
without any local neuro-ectodermal anomaly. Thus, the spine surgeons may be involved in numerous challenging conditions in NF1 patients like scoliosis, spondylolisthesis, and dural ectasia. Because NF1 distresses several organ systems, radiologic spine screening is important in patients with NF1 and patients are likely to profit most from a multidisciplinary treatment policy.

\section{Ethical Considerations}

Compliance with ethical guidelines

There were no ethical considerations to be considered in this research.

Funding

This research did not receive any grant from funding agencies in the public, commercial, or non-profit sectors.

\section{Authors contributions}

Conception and design: Kaveh Haddadi and Saeed Kargar Soleiman Abad; Data collection: Saeed Kargar Soleiman Abad, Seiied Mohammad Hashemie Amir and Mehdi Pooladi; Data analysis and interpretation: Kaveh Haddadi and Saeed Kargar Soleiman Abad; Drafting the article: Kaveh Haddadi and Saeed Kargar Soleiman Abad; Critically revising the article: Kaveh Haddadi; Reviewing submitted version of manuscript: Kaveh Haddadi; Approving the final version of the manuscript: Kaveh Haddadi.

\section{Conflict of interest}

The authors declared no conflict of interest.

\section{Acknowledgements}

We want to thank the Vice President of Research at Mazandaran University of Medical Sciences for their help.

\section{References}

[1] Anderson JL, Gutmann DH. Neurofibromatosis type 1. Handbook of Clinical Neurology. Amsterdam: Elsevier; 2015. pp. 75-86. [DOI:10.1016/ B978-0-444-62702-5.00004-4] [PMID]

[2] Ilgit ET, Vural M, Oguz A, Ozdogan ME. Peripheral arterial involvement in neurofibromatosis type 1: A case report. Angiology. 1999; 50(11):955-8. [DOI:10.1177/000331979905001111 ] [PMID]
[3] Huffman JL, Gahtan V, Bowers VD, Mills JL. Neurofibromatosis and arterial aneurysms. The American Surgeon. 1996; 62(4):311-4. [PMID]

[4] Restrepo CS, Riascos RF, Hatta AA, Rojas R. Neurofibromatosis type 1: Spinal manifestations of a systemic disease. Journal of Computer Assisted Tomography. 2005; 29(4):532-9. [DOI:10.1097/01.rct.0000163705.21892.23] [PMID]

[5] Hirbe AC, Gutmann DH. Neurofibromatosis type 1: A multidisciplinary approach to care. The Lancet Neurology. 2014; 13(8):834-43. [DOI:10.1016/S1474-4422(14)70063-8]

[6] Brems H, Beert E, de Ravel T, Legius E. Mechanisms in the pathogenesis of malignant tumours in neurofibromatosis type 1. The lancet Oncology. 2009; 10(5):508-15. [DOI:10.1016/ S1470-2045(09)70033-6]

[7] O'Connell P, Leach RJ, Ledbetter DH, Cawthon RM, Culver $\mathrm{M}$, Eldridge JR, et al. Fine structure DNA mapping studies of the chromosomal region harboring the genetic defect in neurofibromatosis type 1. American Journal of Human Genetics. 1989; 44(1):51-7. [PMID] [PMCID]

[8] Lammert M, Friedman JM, Kluwe L, Mautner VF. Prevalence of neurofibromatosis 1 in German children at elementary school enrollment. Archives of Dermatology. 2005; 141(1):71-4. [DOI:10.1001/archderm.141.1.71] [PMID]

[9] Crawford AH Jr, Bagamery N. Osseous manifestations of neurofibromatosis in childhood. Journal of Pediatric Orthopaedics. 1986; 6(1):72-88. [DOI:10.1097/01241398-19860100000015] [PMID]

[10] Ratner N, Miller SJ. A RASopathy gene commonly mutated in cancer: The neurofibromatosis type 1 tumour suppressor. Nature Reviews Cancer. 2015; 15(5):290-301. [DOI:10.1038/ nrc3911] [PMID] [PMCID]

[11] Hannan F, Ho I, Tong JJ, Zhu Y, Nurnberg P, Zhong Y. Effect of neurofibromatosis type I mutations on a novel pathway for adenylyl cyclase activation requiring neurofibromin and Ras. Human Molecular Genetics. 2006; 15(7):1087-98. [DOI:10.1093/ hmg/ddl023] [PMID] [PMCID]

[12] Gutmann DH, Wood DL, Collins FS. Identification of the neurofibromatosis type 1 gene product. Proceedings of the National Academy of Sciences. 1991; 88(21):9658-62. [DOI:10.1073/pnas.88.21.9658] [PMID] [PMCID]

[13] Yan J, Chen S, Zhang Y, Li X, Li Y, Wu X, et al. Rac1 mediates the osteoclast gains-in-function induced by haploinsufficiency of Nf1. Human Molecular Genetics. 2008; 17(7):936-48. [DOI:10.1093/hmg/ddm366] [PMID]

[14] Yang FC, Chen S, Robling AG, Yu X, Nebesio TD, Yan J, et al. Hyperactivation of p21ras and PI3K cooperate to alter murine and human neurofibromatosis type 1-haploinsufficient osteoclast functions. The Journal of Clinical Investigation. 2006; 116(11):2880-91. [DOI:10.1172/JCI29092] [PMID] [PMCID]

[15] Wu X, Estwick SA, Chen S, Yu M, Ming W, Nebesio TD, et al. Neurofibromin plays a critical role in modulating osteoblast differentiation of mesenchymal stem/progenitor cells. Human Molecular Genetics. 2006; 15(19):2837-45. [DOI:10.1093/hmg/ dd1208] [PMID]

[16] Poyrazoğlu HG, Baş VN, Arslan A, Bastug F, Canpolat M, Per $\mathrm{H}$, et al. Bone mineral density and bone metabolic markers' status in children with neurofibromatosis type 1 . Journal 
of Pediatric Endocrinology and Metabolism. 2017; 30(2):175-80. [DOI:10.1515/jpem-2016-0092] [PMID]

[17] Mao C, Shah A, Hanson DJ, Howard JM. Von Recklinghausen's disease associated with duodenal somatostatinoma: Contrast of duodenal versus pancreatic somatostatinomas. Journal of Surgical Oncology. 1995; 59(1):67-73. [DOI:10.1002/ jso.2930590116] [PMID]

[18] Rhodes SD, Yang FC. Aberrant myeloid differentiation contributes to the development of osteoporosis in neurofibromatosis type 1. Current Osteoporosis Reports. 2016; 14(1):10-5. [DOI:10.1007/s11914-016-0298-z] [PMID]

[19] Elefteriou F, Kolanczyk M, Schindeler A, Viskochil DH, Hock JM, Schorry EK, et al. Skeletal abnormalities in neurofibromatosis type 1: Approaches to therapeutic options. American Journal of Medical Genetics Part A. 2009; 149(10):2327-38. [DOI:10.1002/ajmg.a.33045] [PMID]

[20] Walker JA, Bernards A. A Drosophila screen identifies neurofibromatosis-1 genetic modifiers involved in systemic and synaptic growth. Rare Diseases (Austin, Tex). 2014; 2:e28341. [DOI:10.4161/rdis.28341] [PMID] [PMCID]

[21] Campen CJ, Gutmann DH. Optic pathway gliomas in neurofibromatosis type 1. Journal of Child Neurology. 2018; 33(1):73-81. [DOI:10.1177/0883073817739509] [PMID] [PMCID]

[22] Gutmann DH, Parada LF, Silva AJ, Ratner N. Neurofibromatosis type 1: Modeling CNS dysfunction. The Journal of Neuroscience: The Official Journal of the Society for Neuroscience. 2012; 32(41):14087-93. [DOI:10.1523/JNEUROSCI.3242-12.2012] [PMID] [PMCID]

[23] Brown JA, Diggs-Andrews KA, Gianino SM, Gutmann DH. Neurofibromatosis-1 heterozygosity impairs CNS neuronal morphology in a cAMP/PKA/ROCK-dependent manner. Molecular and Cellular Neurosciences. 2012; 49(1):13-22. [DOI:10.1016/j.mcn.2011.08.008] [PMID] [PMCID]

[24] Tsirikos AI, Saifuddin A, Noordeen MH. Spinal deformity in neurofibromatosis type-1: Diagnosis and treatment. European Spine Journal : Official Publication of the European Spine Society, the European Spinal Deformity Society, and the European Section of the Cervical Spine Research Society. 2005; 14(5):427-39. [DOI:10.1007/s00586-004-0829-7] [PMID] [PMCID]

[25] Nathan ST, Mangano FT, Crawford AH. Spondyloptosis of the cervical spine in a patient with neurofibromatosis type 1: A case report and review of the literature. JBJS Case Connector. 2013; 3(1):e5. [DOI:10.2106/JBJS.CC.L.00135] [PMID]

[26] Albayrak BS, Gorgulu A, Kose T. A case of intra-dural malignant peripheral nerve sheath tumor in thoracic spine associated with neurofibromatosis type 1 . Journal of Neuro-oncology. 2006; 78(2):187-90. [DOI:10.1007/s11060-005-9086-9] [PMID]

[27] Neurofibromatosis. Conference statement. National Institutes of Health Consensus Development Conference. Archives of Neurology. 1988; 45(5):575-8. [DOI:10.1001/archneur.1988.00520290115023] [PMID]

[28] Lobbous M, Bernstock JD, Coffee E, Friedman GK, Metrock LK, Chagoya G, et al. An Update on neurofibromatosis type 1-associated gliomas. Cancers. 2020; 12(1):114. [DOI:10.3390/ cancers12010114] [PMID] [PMCID]

[29] Rodari G, Scuvera G, Ulivieri FM, Profka E, Menni F, Saletti $\mathrm{V}$, et al. Progressive bone impairment with age and pubertal development in neurofibromatosis type I. Archives of Osteoporosis. 2018; 13(1):93. [DOI:10.1007/s11657-018-0507-8] [PMID]

[30] Alwan S, Tredwell SJ, Friedman JM. Is osseous dysplasia a primary feature of neurofibromatosis 1 (NF1)? Clinical Genetics. 2005; 67(5):378-90. [DOI:10.1111/j.1399-0004.2005.00410.x] [PMID]

[31] Hu Z, Liu Z, Qiu Y, Xu L, Yan H, Zhu Z. Morphological differences in the vertebrae of scoliosis secondary to neurofibromatosis type 1 with and without paraspinal neurofibromas. Spine. 2016; 41(7):598-602. [DOI:10.1097/ BRS.0000000000001455] [PMID]

[32] Illés T, Halmai V, de Jonge T, Dubousset J. Decreased bone mineral density in neurofibromatosis-1 patients with spinal deformities. Osteoporosis International: A Journal Established as Result of Cooperation between the European Foundation for Osteoporosis and the National Osteoporosis Foundation of the USA. 2001; 12(10):823-7. [DOI:10.1007/ s001980170032] [PMID]

[33] Debnam JM, Mahfouz YM, Ketonen L, Slopis JM, McCutcheon IE, Guha-Thakurta N. Multidetector CT with 3-dimensional volume rendering in the evaluation of the spine in patients with Neurofibromatosis type 1: A retrospective review in 73 patients. Scoliosis. 2014; 9:15. [DOI:10.1186/17487161-9-15] [PMID] [PMCID]

[34] Sulaiman AR, Nordin S, Faisham WI, Zulmi W, Halim AS. Residual non:union: following vascularised fibular graft treatment for congenital pseudarthrosis of the tibia: A report of two cases. Journal of Orthopaedic Surgery. 2006; 14(1):64-6. [DOI:10.1177/230949900601400114] [PMID]

[35] Brunetti-Pierri N, Doty SB, Hicks J, Phan K, Mendoza-Londono R, Blazo M, et al. Generalized metabolic bone disease in Neurofibromatosis type I. Molecular Genetics and Metabolism. 2008; 94(1):105-11. [DOI:10.1016/j.ymgme.2007.12.004] [PMID] [PMCID]

[36] Herrera-Soto JA, Crawford AH, Loveless EA. Ossifying subperiosteal hematoma associated with neurofibromatosis type 1. Diagnostic hesitations: A case report and literature review. Journal of Pediatric Orthopaedics B. 2005; 14(1):51-4 [DOI:10.1097/01202412-200501000-00009] [PMID]

[37] Szudek J, Birch P, Friedman JM. Growth in North American white children with neurofibromatosis 1 (NF1). Journal of Medical Genetics. 2000; 37(12):933-8. [DOI:10.1136/ jmg.37.12.933] [PMID] [PMCID]

[38] Vitale MG, Guha A, Skaggs DL. Orthopaedic manifestations of neurofibromatosis in children: An update. Clinical Orthopaedics and Related Research. 2002; (401):107-18. [DOI:10.1097/00003086-200208000-00013] [PMID]

[39] Núñez-Farías AC, Borzutzky A, Morales PS, Zunino R, del Villar S. Severe spinal neurofibromatosis in a child. The Journal of Pediatrics. 2012; 161(2):368-e1. [DOI:10.1016/j. jpeds.2012.03.056] [PMID]

[40] Mesfin A, Bakhsh WR, Chuntarapas T, Riew KD. Cervical Scoliosis: Clinical and radiographic outcomes. Global Spine Journal. 2016; 6(1):7-13. [DOI:10.1055/s-0035-1554776] [PMID] [PMCID]

[41] Ramachandran M, Tsirikos AI, Lee J, Saifuddin A. Wholespine magnetic resonance imaging in patients with neurofibromatosis type 1 and spinal deformity. Journal of Spinal 
Disorders \& Techniques. 2004; 17(6):483-91. [DOI:10.1097/01. bsd.0000133466.97241.50] [PMID]

[42] Martin S, Gillespie A, Wolters PL, Widemann BC. Experiences of families with a child, adolescent, or young adult with neurofibromatosis type 1 and plexiform neurofibroma evaluated for clinical trials participation at the National Cancer Institute. Contemporary Clinical Trials. 2011; 32(1):10-5. [DOI:10.1016/j.cct.2010.10.004] [PMID] [PMCID]

[43] Tsirikos AI, Dhokia R, Wordie S. Rotatory dislocation of the spine in dystrophic kyphoscoliosis secondary to neurofibromatosis type 1. Journal of Central Nervous System Disease. 2018; 10:1179573518819484. [DOI:10.1177/1179573518819484] [PMID] [PMCID]

[44] Larson AN, Ledonio CGT, Brearley AM, Sucato DJ, Carreon LY, Crawford AH, et al. Predictive value and interrater reliability of radiographic factors in neurofibromatosis patients with dystrophic scoliosis. Spine Deformity. 2018; 6(5):560-7. [DOI:10.1016/j.jspd.2018.02.011] [PMID] [PMCID]

[45] Tauchi R, Tsuji T, Cahill PJ, Flynn JM, Flynn JM, Glotzbecker M, et al. Reliability analysis of Cobb angle measurements of congenital scoliosis using X-ray and 3D-CT images. European Journal of Orthopaedic Surgery \& Traumatology: Orthopedie Traumatologie. 2016; 26(1):53-7. [DOI:10.1007/s00590-0151701-7] [PMID]

[46] Jia F, Cui X, Wang G, Liu X, Sun J. Spontaneous rotational dislocation of the lumbar spine in type 1 neurofibromatosis: A case report and literature review. Medicine (Baltimore). 2019; 98(16):e15258. [PMID]

[47] Singh K, Samartzis D, An HS. Neurofibromatosis type I with severe dystrophic kyphoscoliosis and its operative management via a simultaneous anterior-posterior approach: A case report and review of the literature. The Spine Journal : Official Journal of the North American Spine Society. 2005; 5(4):461-6. [DOI:10.1016/j.spinee.2004.09.015] [PMID]

[48] Laws J, Pallis C. Spinal deformities in neurofibromatosis. The Journal of Bone and Joint Surgery British Volume. 1963, 45(4):674-82. [DOI:10.1302/0301-620X.45B4.674] [PMID]

[49] Crawford AH, Herrera-Soto J. Scoliosis associated with neurofibromatosis. Orthopedic Clinics of North America. 2007; 38(4):553-62. [DOI:10.1016/j.ocl.2007.03.008] [PMID]

[50] Kurucan E, Bernstein DN, Thirukumaran C, Jain A, Menga EN, Rubery PT, et al. National trends in spinal fusion surgery for neurofibromatosis. Spine Deformity. 2018; 6(6):712-8 [DOI:10.1016/j.jspd.2018.03.012] [PMID]

[51] Palsgrove DN, Brosnan-Cashman JA, Giannini C, Raghunathan A, Jentoft $M$, Bettegowda C, et al. Subependymal giant cell astrocytoma-like astrocytoma: A neoplasm with a distinct phenotype and frequent neurofibromatosis type-1-association. Modern Pathology: An Official Journal of the United States and Canadian Academy of Pathology, Inc. 2018; 31(12):1787-800. [DOI:10.1038/s41379-018-0103-x] [PMID] [PMCID]

[52] Iacoangeli M, Di Rienzo A, Colasanti R, Alvaro L, Nocchi N, Polonara G, et al. Rare synchronous association of vestibular schwannoma and indolent insular oligodendroglioma in a patient without neurofibromatosis: Controversial issue of timing for surgical treatment of asymptomatic lowgrade gliomas. Onco Targets and Therapy. 2012; 5:357-61. [DOI:10.2147/OTT.S39276] [PMID] [PMCID]
[53] Chamoun RB, Whitehead WE, Dauser RC, Luerssen TG, Okcu $\mathrm{MF}$, Adesina AM, et al. Primary disseminated intradural malignant peripheral nerve sheath tumor of the spine in a child: Case report and review of the literature. Pediatric Neurosurgery. 2009; 45(3):230-6. [DOI:10.1159/000224621] [PMID]

[54] Ferrer M, Gosline SJC, Stathis M, Zhang X, Guo X, Guha R, et al. Pharmacological and genomic profiling of neurofibromatosis type 1 plexiform neurofibroma-derived schwann cells. Scientific Data. 2018; 5:180106. [DOI:10.1038/sdata.2018.106] [PMID] [PMCID]

[55] Abdessayed N, Gupta R, Mestiri S, Bdioui A, Trimech M, Mok$\mathrm{ni}$ M. Rare triad of periampullary carcinoid, duodenal gastrointestinal stromal tumor and plexiform neurofibroma at hepatic hilum in neurofibromatosis type 1: A case report. BMC Cancer. 2017; 17(1):579. [DOI:10.1186/s12885-017-3567-z] [PMID] [PMCID]

[56] Hernández-Martín A, Duat-Rodríguez A. An update on neurofibromatosis type 1: Not just café-au-lait spots, freckling, and neurofibromas. An update. Part I. Dermatological clinical criteria diagnostic of the disease. Actas Dermo-SifiliOgraficas. 2016 107(6):454-64. [DOI:10.1016/j.ad.2016.01.004] [PMID]

[57] Dehal N, Arce Gastelum A, Millner PG. Neurofibromatosisassociated diffuse lung disease: A case report and review of the literature. Cureus. 2020; 12(6):e8916. [DOI:10.7759/cureus.8916] [PMID] [PMCID]

[58] Allaway RJ, Gosline SJC, La Rosa S, Knight P, Bakker A, Guinney J, et al. Cutaneous neurofibromas in the genomics era: Current understanding and open questions. British Journal of Cancer. 2018; 118(12):1539-48. [DOI:10.1038/s41416-018-0073-2] [PMID] [PMCID]

[59] Kebudi R, Cakir FB, Gorgun O. Interferon-a for unresectable progressive and symptomatic plexiform neurofibromas. Journal of Pediatric Hematology/Oncology. 2013; 35(3):e115-7. [DOI:10.1097/MPH.0b013e318270cd24] [PMID]

[60] Staser K, Yang FC, Clapp DW. Pathogenesis of plexiform neurofibroma: Tumor-stromal/hematopoietic interactions in tumor progression. Annual Review of Pathology. 2012; 7:469-95 [DOI:10.1146/annurev-pathol-011811-132441] [PMID] [PMCID]

[61] Messersmith L, Krauland K. Neurofibroma. Stat pearls [Internet]. 2020 [Update 2020 August 10]. https:/ /www.ncbi.nlm.nih gov/books/NBK539707/

[62] Messiaen L, Riccardi V, Peltonen J, Maertens O, Callens T, Karvonen SL, et al. Independent NF1 mutations in two large families with spinal neurofibromatosis. Journal of Medical Genetics. 2003; 40(2):122-6. [DOI:10.1136/jmg.40.2.122] [PMID] [PMCID]

[63] Topsakal C, Akdemir I, Tiftikci M, Ozercan I, Aydin Y. Malignant schwannoma of the sciatic nerve originating in a spinal plexiform neurofibroma associated with neurofibromatosis type 1--case report. Neurologia Medico-Chirurgica. 2001; 41(11):551-5. [DOI:10.2176/nmc.41.551] [PMID]

[64] Ahlawat S, Blakeley J, Montgomery E, Subramaniam RM, Belzberg A, Fayad LM. Schwannoma in neurofibromatosis type 1: A pitfall for detecting malignancy by metabolic imaging. Skeletal Radiology. 2013; 42(9):1317-22. [DOI:10.1007/s00256-013-1626-3] [PMID] [PMCID]

[65] Han KS, Lee KM, Kim BJ, Kwun BD, Choi SK, Lee SH. Lifethreatening hemothorax caused by spontaneous extracranial vertebral aneurysm rupture in neurofibromatosis type 1 . World Neurosurgery. 2019; 130:157-9. [DOI:10.1016/j.wneu.2019.07.007] [PMID] 
[66] Derdabi I, Jouadi HE, Edderai M. Dural ectasia: A manifestation of type 1 neurofibromatosis. The Pan African Medical Journal. 2018; 31:226. [DOI:10.11604/pamj.2018.31.226.9797] [PMID] [PMCID]

[67] Nakamura H, Kudo T, Kobayashi H, Taguchi Y. Successfully treated traumatic dislocation of a thoracic vertebra caused by minor trauma in a patient with neurofibromatosis type I a case report and literature review. NMC Case Report Journal. 2018; 5(4):77-81. [DOI:10.2176/nmccri.cr.2018-0051] [PMID] [PMCID]

[68] Yong-Hing K, Kalamchi A, MacEwen GD. Cervical spine abnormalities in neurofibromatosis. The Journal of Bone and Joint Surgery. American Volume. 1979; 61(5):695-9. [DOI:10.2106/00004623-197961050-00007]

[69] Goffin J, Grob D. Spondyloptosis of the cervical spine in neurofibromatosis: A case report. Spine. 1999; 24(6):587-90. [DOI:10.1097/00007632-199903150-00020] [PMID]

[70] Craig JB, Govender S. Neurofibromatosis of the cervical spine. A report of eight cases. The Journal of Bone and Joint Surgery British Volume. 1992; 74(4):575-8. [DOI:10.1302/0301-620X.74B4.1624519] [PMID]

[71] Toyoda K, Taguchi T, Kaneko K, Kato Y, Imajo Y, Imagama T. High-grade L5 spondylolisthesis associated with dural ectasia in neurofibromatosis. Journal of Orthopaedic Science. 2005 10(2):233-6. [DOI:10.1007/s00776-004-0869-1] [PMID]

[72] Schievink WI, Piepgras DG. Cervical vertebral artery aneurysms and arteriovenous fistulae in neurofibromatosis type 1: Case reports. Neurosurgery. 1991; 29(5):760-5. [DOI:10.1227/00006123199111000-00020]

[73] Hieda M, Toyota N, Kakizawa H, Hirai N, Tachikake T, Yahiro $\mathrm{Y}$, et al. Endovascular therapy for massive haemothorax caused by ruptured extracranial vertebral artery aneurysm with neurofibromatosis Type 1. The British Journal of Radiology. 2007; 80(952):e81-4. [DOI:10.1259/bjr/47379807] [PMID]

[74] Peyre M, Ozanne A, Bhangoo R, Pereira V, Tadié M, Lasjaunias $P$, et al. Pseudotumoral presentation of a cervical extracranial vertebral artery aneurysm in neurofibromatosis type 1 : Case report. Neurosurgery. 2007; 61(3):E658. [DOI:10.1227/01. NEU.0000290919.47847.D7] [PMID]

[75] Uneda A, Suzuki K, Okubo S, Hirashita K, Yunoki M, Yoshino K. Neurofibromatosis type 1-associated extracranial vertebral artery aneurysm complicated by vertebral arteriovenous fistula after rupture: Case report and literature review. World Neurosurgery. 2016; 96:609.e13-609.e18. [DOI:10.1016/j.wneu.2016.09.036] [PMID]

[76] Moratti C, Andersson T. Giant extracranial aneurysm of the internal carotid artery in neurofibromatosis type 1 . A case report and review of the literature. Interventional Neuroradiology : Journal of Peritherapeutic Neuroradiology, Surgical Procedures and Related Neurosciences. 2012; 18(3):341-7. [DOI:10.1177/15910199 1201800315] [PMID] [PMCID]

[77] Morvan T, de Broucker F, de Broucker T. Subarachnoid hemorrhage in neurofibromatosis type 1: Case report of extracranial cerebral aneurysm rupture into a meningocele. Journal of Neuroradiology. 2011; 38(2):125-8. [DOI:10.1016/j.neurad.2010.11.001] [PMID]

[78] Mitsui Y, Nakasaka Y, Akamatsu M, Ueda H, Kihara M, Takahashi M. Neurofibromatosis type 1 with basilar artery fusiform aneurysm manifesting Wallenberg's syndrome. Internal Medicine. 2001; 40(9):948-51. [DOI:10.2169/internalmedicine.40.948] [PMID]
[79] Hoffmann KT, Hosten N, Liebig T, Schwarz K, Felix R. Giant aneurysm of the vertebral artery in neurofibromatosis type 1: Report of a case and review of the literature. Neuroradiology. 1998; 40(4):245-8. [DOI:10.1007/s002340050576] [PMID]

[80] Ntenga P, Kabulo K, Fogang Y, Bugeme M, Boubacar S, Salaheddine $\mathrm{M}$, et al . Cervical spinal cord compression and demyelinating neuropathy complicating neurofibromatosis type 1: About a case. Journal of Neurology and Neurobiology. 2017; 3(2).1-3. [DOI:10.16966/2379-7150.141]

[81] Ferner RE, Hughes RA, Hall SM, Upadhyaya M, Johnson MR. Neurofibromatous neuropathy in neurofibromatosis 1 (NF1). Journal of Medical Genetics. 2004; 41(11):837-41. [DOI:10.1136/jmg.2004.021683] [PMID] [PMCID]

[82] Haddadi K. Outlines and outcomes of instrumented posterior fusion in the pediatric cervical spine: A review article. Journal of Pediatrics Review. 2016; 4(1). [DOI:10.17795/jpr-4765]

[83] Haddadi K. Pediatric lumbar disc herniation: A review of manifestations, diagnosis and management. Journal of Pediatrics Review. 2016; 4(1). http://jpr.mazums.ac.ir/article1-118-en.html

[84] Haddadi K. Pediatric endoscopic third ventriculostomy: A narrative review of current indications, techniquesandcomplications. Journal of Pediatrics Review. 2016; 4(2):31-7. [DOI:10.17795/jpr-5074]

[85] Alaedini K, Haddadi K, Asadian L. A review of neurobehavioral challenges in children exposed prenatally to intrauterine opioid. Journal of Pediatrics Review. 2017; 5(2):31-5. [DOI:10.5812/jpr.9234] 
This Page Intentionally Left Blank 